\title{
A gramatização de uma língua: o caso de Libras
}

\author{
Enézia de Cassia de Jesus ${ }^{1}$
}

Núbia Rabelo Bakker Faria²

\section{Resumo}

Neste trabalho, articulamos teoricamente o processo de instrumentalização da Libras com o que aconteceu com às línguas vernáculas durante o Renascimento, quando bouve o que Auroux (2014) denomina movimento de gramatização massiva das línguas do mundo. Diferentemente do que ocorreu com os vernáculos europeus, a escassez de material escrito é notória e a "alfabetização" dos surdos brasileiros em língua de sinais é ainda bastante incipiente. Atribuimos esse fato à hegemonia da língua portuguesa, mas levantamos a bipótese de que o aparecimento de novas tecnologias com recurso à imagem com movimento desfavorece a percepção da necessidade de uma escrita entre os surdos. Desenvolveremos nossa reflexão a partir da discussão bistoriográfica de Auroux (2014) e de autores que tratam da descrição da Libras e da criação e de um sistema de escrita para línguas de sinais, como Capovilla e outros (2001; 2004; 2011; 2013) e Barros (2008; 2015).

Palavras-chave: Libras. Gramatização. Escrita. Povo surdo

\footnotetext{
${ }^{1}$ Faculdade de Letras da Universidade Federal de Alagoas (Fale/Ufal). E-mail: enezia.cassia@hotmail.com.

${ }^{2}$ Faculdade de Letras da Universidade Federal de Alagoas (Fale/Ufal). E-mail: nrbfaria@uol.com.br.
} 


\section{Introdução}

A Língua Brasileira de Sinais (doravante Libras) torna-se língua oficial do Brasil em abril de 2002, mediante a Lei 10.436, homologada pelo Decreto 5.626 de 2005. Quadros e Schmiedt assinalam que, "a partir de então, a educação de surdos no Brasil deve ser bilíngue, garantindo o acesso à educação por meio da língua de sinais e o ensino da língua portuguesa escrita como segunda língua” (2006, p. 17).

Esse reconhecimento da Libras como língua oficial brasileira foi acompanhado por esforços para descrever e instrumentalizar essa língua, tendo como base a criação de instrumentos linguísticos, como dicionários e gramáticas. Esses, conforme Auroux (2014), têm efeitos decisivos sobre a percepção das línguas e as práticas linguísticas humanas. Como reflexo desse recente processo de oficialização, destaca-se, ainda, a busca por uma escrita para Libras. Existem hoje em circulação algumas propostas de sistemas de escrita para línguas de sinais ${ }^{3}$. Para atender às exigências da discussão que faremos a seguir, mencionaremos o SignWriting (doravante SW) e a Escrita das Línguas de Sinais (doravante EliS).

Neste trabalho, defendemos ser possível articular teoricamente o processo de gramatização da Libras com o que aconteceu com as línguas vernáculas durante o período do Renascimento. Nesse período histórico, há o que Auroux (2014) denomina movimento de gramatização massiva das línguas do mundo, isto é, o surgimento de um número significativo de novas gramáticas e dicionários, na esteira da criação dos Estados modernos europeus e a constituição de nações que têm um povo reunido, dentre outras coisas, a partir de uma língua oficial.

Para desenvolvermos nossa reflexão, apoiamo-nos teoricamente na discussão historiográfica empreendida por Auroux (2014), além de autores que tratam do processo de descrição da Libras e da criação de um sistema de escrita para línguas de sinais, dentre eles, Capovilla e outros (2001; 2004; 2011; 2013) e Barros (2008; 2015).

\footnotetext{
${ }^{3}$ Além do SignWriting e do EliS, que mencionaremos no texto, existe ainda o Hamburg Sign Language Notation System (HamNoSys), que foi criado na Universidade de Hamburgo, Alemanha, por Prillwitz e seus colaboradores, em 1989, e a Escrita SEL, criada pela professora Adriana Stella Cardoso Lessa de Oliveira, em 2009, na Bahia.
} 


\section{A gramatização das línguas: Renascimento}

O Renascimento compreende o período de tempo que vai, aproximadamente, do fim do século XIV ao início do século XVII, tendo seu ponto de partida na Itália, estendendo-se, posteriormente, a todo o continente europeu. Este período é caracterizado pelo abalo das estruturas medievais e passagem para a chamada Idade Modena. No plano cultural, o Renascimento é marcado pelo retorno aos clássicos em busca dos valores humanos, acarretando uma ruptura com o pensamento teocêntrico presente no período medieval. Importantes acontecimentos artísticos e culturais na pintura, na escultura, na arquitetura e na música marcaram esse momento. Houve também a expansão do "Velho Mundo” com as Grandes Navegações, que possibilitaram o desenvolvimento comercial, seguido de mudanças sociais, religiosas, econômicas e políticas que afetaram radicalmente a Europa Ocidental, espalhando-se, em seguida, para o resto do mundo.

No caso de nossa discussão, o período do Renascimento é particularmente importante, tendo em vista a invenção da imprensa, o surgimento dos Estados nacionais modernos e a consequente elaboração de gramáticas das diversas línguas vernáculas europeias, a expansão marítima e a descoberta de novas línguas.

Durante o Renascimento, com a formação dos Estados europeus, tornou-se imprescindível a escolha de uma língua nacional. A esse respeito, Robins (1979, p. 78) destaca:

O nascimento de Estados nacionais, o sentimento patriótico e o fortalecimento do governo central levaram ao reconhecimento como língua oficial de uma das variedades faladas em determinado território; as pessoas julgavam ser uma obrigação promover o uso e o cultivo de sua própria língua nacional (ROBINS, 1979, p. 78).

Auroux (2014, p. 49) chama atenção para o efeito linguístico da disputa entre as nações emergentes, afirmando que a "expansão das nações acarreta indiscutivelmente uma situação de luta entre elas, o que se traduz, ao final, por uma concorrência, reforçada porque institucionalizada, entre as línguas".

Cumpre destacar, ainda, a relevância da invenção da imprensa no decorrer do período renascentista. Nas palavras de Auroux (2014, p. 51), “o fenômeno da escrita da língua muda de dimensão". A imprensa impulsiona a distribuição de textos escritos, a circulação de livros, a propagação de novas ideias, o estudo de novas línguas, a 
padronização do sistema de escrita, dentre outras importantes consequências. De acordo com Robins,

\begin{abstract}
A invenção da imprensa possibilitou a difusão da cultura em largas proporções; e o nascimento de uma classe média de comerciantes estendeu os benefícios da educação a círculos cada vez mais amplos da sociedade e estimulou o estudo de modernas línguas estrangeiras. (ROBINS, 1979, p. 78).
\end{abstract}

Auroux (2014) assinala os contatos linguísticos que foram possíveis durante o Renascimento devido à propagação dos textos escritos e o papel exercido pelo livro impresso nesse momento.

[...] os contatos linguísticos se tornaram um dos elementos determinantes dos saberes linguísticos codificados e as gramáticas se tornam as peças mestras de uma técnica do conhecimento das línguas. Em seguida, o desenvolvimento do livro impresso dá a este fenômeno uma difusão incomparável (AUROUX, 2014, p. 29).

A disponibilidade de textos proporcionada pela nova tecnologia, representada pela imprensa e pela expansão marítima europeia a outros continentes abre caminho para os estudos de novas línguas. Desde então, observa Robins (1979, p. 75), “ampliam-se os horizontes linguísticos: as obras de gramáticos não europeus começam a causar impactos na tradição europeia, as línguas vivas da Europa passam a ser sistematicamente estudadas $[\cdots]^{\prime}$.

\title{
Gramatização e escrita
}

Nesse cenário do Renascimento rapidamente esboçado acima, Auroux discute o que chama de gramatização das línguas modernas, definida como "o processo que conduz a descrever e a instrumentalizar uma língua na base de duas tecnologias, que são ainda hoje os pilares de nosso saber metalinguístico: a gramática e o dicionário” (AUROUX, 2014, p. 65).

Defende o autor que a gramatização das línguas tem efeito semelhante à Revolução Industrial para o mundo ocidental e que, depois da invenção da escrita, tal como a concebemos ainda hoje, a gramatização das línguas foi o grande acontecimento. 
A gramatização exerce um papel fundamental na manutenção e preservação das línguas, tendo em vista que as línguas que têm unicamente a modalidade oral acabam se perdendo na ausência de instrumentos linguísticos que assegurariam sua padronização. Para o autor, "a gramatização modificou profundamente a ecologia da comunicação e o estado do patrimônio linguístico da humanidade" (AUROUX, 2014, p. 9) e, com isso, "as línguas, pouco ou menos 'não-instrumentalizadas', foram por isso mesmo mais expostas ao que convém chamar linguicídio, quer seja ele voluntário ou não” (p. 70).

Referindo-se à língua latina durante o período medieval, afirma Auroux que, por volta dos séculos VII a IX, esta já não exerce papel vernacular na Europa Ocidental. No entanto, permanece como língua de administração, cultura intelectual e religiosa entre os descendentes neolatinos, assim como os não latinos, como falantes de línguas célticas e germânicas. A gramática latina se constituirá numa técnica de aprendizagem desta que será, então, uma segunda língua.

Foi necessário primeiro que a gramática de uma língua já gramaticalizada fosse massivamente empregada para fins de pedagogia linguística, [...] para que a gramática se tornasse - o que tomará um tempo considerável - uma técnica geral de aprendizagem, aplicável a toda língua, aí compreendida a lingua materna (AUROUX, 2014, p. 42) [grifos nossos].

A gramática, portanto, torna-se, simultaneamente, uma técnica pedagógica de aprendizagem das línguas, inclusive a materna, e um modo de descrevê-las, acabando por se tornar um importantíssimo instrumento na relação dos europeus com os povos dominados e colonizados ao redor do mundo.

É importante considerar a necessidade da escrita para a elaboração das gramáticas e dicionários renascentistas. Assim sendo, a "alfabetização" dos vernáculos, isto é, a criação de um sistema de escrita para as variedades dialetais alçadas à condição de línguas oficiais, é concomitante ao aparecimento desses instrumentos linguísticos.

Vale aqui insistir sobre o destaque dado por Auroux (2014) à escrita. O autor chama atenção para a multiplicidade do saber linguístico, diferenciando o saber epilinguístico, aquele que é executado de maneira inconsciente por qualquer falante, do saber metalinguístico, a partir do qual é construída uma metalinguagem para falar sobre o funcionamento da linguagem. Afirma, ainda, que a reflexão metalinguística surge como consequência do fato de haver escrita, pois esta proporciona o processo de objetivação da linguagem: uma "representação metalinguística considerável e sem equivalente anterior" 
(AUROUX, 2014, p. 20). Assim sendo, Auroux defende a tese de que a escrita passa de resultado para condição de possibilidade do surgimento do saber metalinguístico, invertendo a lógica do senso comum, que tende a atribuir à reflexão consciente sobre a linguagem a causa da invenção da escrita.

Portanto, é a escrita que possibilita um pensar científico sobre as questões da linguagem humana, constituindo-se num dos fatores necessários ao aparecimento das ciências da linguagem, que "remontam à virada dos terceiro e segundo milênios antes de nossa era, entre os acadianos" (AUROUX, 2014, p. 8). Em outras palavras, para o autor, como insiste em diferentes momentos de sua obra, as ciências da linguagem não surgem com os estudos comparatistas do século XIX, mas muito antes, com o aparecimento da escrita. Com isso, Auroux ressalta o papel fundamental da escrita para a história das representações linguísticas.

\section{A gramatização da Libras: o "povo surdo"}

Vimos que as gramáticas e os dicionários são instrumentos linguísticos objetivamente criados para a uniformização de uma língua. Vimos ainda que Auroux (2014) enfatiza que, durante o Renascimento, a gramatização surgiu da necessidade de oficializar as línguas vernáculas, no período de constituição das nações europeias. Ainda no Renascimento, gramáticas e dicionários tornaram-se instrumentos de ensino da língua materna e a concorrência entre as nações estabeleceu uma nova relação política, na qual a língua exerceu um papel central enquanto elemento fundador de identidade nacional.

Aos moldes do que se observa nesse período, constatamos que fica cada vez mais explicitada a relação entre a formação da identidade surda e a separação estabelecida entre o português e a Libras, referida como a língua nativa dos surdos. Isso pode ser observado num levantamento preliminar que fizemos, onde figuram vários "instrumentos linguísticos", sobretudo dicionários de Libras: Minidicionário Ilustrado de Libras, elaborado pelo Centro de Formação de Profissionais da Educação e de Atendimento às Pessoas com Surdez; Dicionário Enciclopédico Ilustrado Trilingue da Lingua de Sinais Brasileira (CAPOVILLA; RAPHAEL, 2001); o Novo Dicionário Trilíngue Ilustrado: português, inglês e Libras (CAPOVILLA; RAPHAEL; MAURÍCIO, 2013); Dicionário Ilustrado de Libras (BRANDÃO, 2011); Dicionário da Lingua de Sinais Brasileira: Acessibilidade Brasil, versão 2.1 (LIRA; 
SOUZA, 2008); Dicionário Libras (disponível em http://www.dicionariolibras.com.br/), elaborado pela Federação Nacional de Educação dos Sursos (Feneis), dentre outros.

Podemos ler, por exemplo, na apresentação da primeira versão, de 2001, do monumental Dicionário Enciclopédico Ilustrado Trilingue: Lingua de Sinais Brasileira, de Capovilla e outros, feita por Oliver Sacks (2001), a seguinte afirmação:

Se a Libras é a língua nativa do surdo, ela deve ser ponte para adquirir o português, e não o contrário. Não faz sentido tentar usar uma língua estrangeira como ponte para aquisição da língua nativa. Por isso é preciso criar um instrumento capaz de dar ao surdo acesso direto aos sinais da Libras, e não apenas um acesso mediado pela glosa em português (SACKS, 2001, p. 15).

Destacamos o uso explícito dos adjetivos "nativa" e "estrangeira", com que Sacks se refere à Libras e ao português, respectivamente, aludindo à já mencionada concorrência entre línguas de povos distintos. Aliás, o autor, no prefácio de uma obra anterior - Vendo vozes -, afirma, de forma ainda mais categórica: "Ainda que jamais tenha esquecido a condição 'médica' dos surdos, fui então levado a vê-los sob uma nova luz, 'étnica', como um povo, com uma língua distinta, com sensibilidade e cultura próprias" (SACKS, 2010, p. $9)$.

É bastante evidente o processo de gramatização que se repete em Libras, com a elaboração de dicionários e gramáticas, na base das línguas europeias, sob a influência do mundo latino que unificou o saber linguístico ocidental, a partir do que Auroux (2014, p. 44) chama de rede de conhecimento: "A gramatização (a base do latim) de um vernáculo europeu pode igualmente servir de partida para uma outra língua e lhe transmitir sua 'latinidade"'.

A introdução do livro de Ferreira (2010), Por uma gramática de língua de sinais, é bastante significativa para a nossa discussão:

[Libras] É uma língua natural surgida entre os surdos brasileiros da mesma forma que o Português, o Inglês, o Francês, etc. surgiram ou se derivaram de outras línguas para servir aos propósitos linguísticos daqueles que as usam (FERREIRA, 2010, p. 11).

Auroux (2014, p. 66) elenca os elementos primordiais de uma gramática: a) categorização das unidades; b) exemplos e c) regras mais ou menos explícitas para construir enunciados (os exemplos escolhidos podem tomar seu lugar). Além disso, o autor chama 
atenção para a interferência da noção de regra, como uma forma de contenção da variação linguística típica das línguas não "instrumentalizadas". Mais uma vez, vemos esse fenômeno se apresentar em Libras:

[...] apesar da diferença existente entre línguas de sinais e línguas orais, ambas seguem os mesmos princípios pelo fato de possuírem um léxico, isto é, um conjunto de símbolos convencionais, e uma gramática, ou seja, um sistema de regras que rege o uso desses símbolos (PEREIRA et al., 2011, p. 59).

De acordo com o levantamento feito por nós, foram encontradas várias obras que usam a terminologia da gramática, não necessariamente uma gramática específica de Libras. Nestas obras, pode-se observar o emprego da metalinguagem usada para uma construção gramatical, com base na gramática da Língua Portuguesa, que, dessa forma, transmite à Libras sua "latinidade".

Para os empréstimos lexicais, a Libras desenvolveu um alfabeto manual que é constituído de Configurações de Mão constitutivas dos sinais, as quais representam as letras do alfabeto da língua portuguesa. Através da "datilografia" ou soletração digital, este alfabeto é utilizado para traduzir nomes próprios ou palavras para as quais não se encontram equivalentes prontos em Libras ou para explicar o significado de um sinal a um ouvinte (FERREIRA, 2010, p. 22).

Considerando o fato de, na maioria dos casos, a Libras ser majoritariamente ensinada ao surdo quando este já passou da primeira infância, os instrumentos linguísticos encontram-se, de forma particular, destinados ao ensino da Libras. Confirma-se o que mencionamos acima, ao falarmos de como as gramáticas sustentaram uma pedagogia linguística, incluindo-se aí a língua materna. Acrescente-se a isso o objetivo declarado de constituição de uma identidade linguística e cultural, separando-se, assim, da cultura e da língua portuguesa dos ouvintes brasileiros.

No processo de construção dos instrumentos linguísticos na Língua Brasileira de Sinais, nota-se, explicitamente, o apelo à unificação de um povo em torno de uma língua materna própria, como ocorreu na formação das nações europeias no período do Renascimento.

[...] a língua carrega consigo a identidade e a cultura de um povo. Os surdos, assim como outras comunidades linguísticas, constroem a sua identidade e cultura através da interação com as pessoas iguais a si mesmos, no caso dos surdos, nas mesmas condições da surdez - com o povo surdo. Portanto, o contato com seu grupo faz com que se haja a identificação com a língua de sinais e com uma identidade e cultura 
peculiar às suas raízes (GRASSI et al., 2011, p. 65) [grifo nosso] ${ }^{4}$.

\section{A “alfabetização" da Libras e dos surdos brasileiros}

O desenvolvimento de sistemas de escrita para as línguas de sinais, tais como o Signwriting (SW) e a Escrita das Línguas de Sinais (EliS), compõe o quadro traçado por Auroux (2014) na formação das nações modernas.

O SW foi criado por Valerie Sutton na década de 1970, a partir um sistema usado para escrever movimentos de dança. Conforme Stumpf (2005, p. 51), esse sistema de escrita "pode registrar qualquer língua de sinais do mundo sem passar pela tradução da língua falada. Cada língua de sinais vai adaptá-lo a sua própria ortografia”.

Segundo Capovilla e outros (2013), no prefácio do Novo Deit-Libras, a criação de um dicionário no qual há um registro escrito de Libras, no caso o SW, tem como intuito apresentar um sistema de escrita visual de forma acessível, que proporcione ao surdo a possibilidade de ler e escrever em Libras e fazer uso desta escrita como meio de aperfeiçoamento e registro de sua língua, e em seguida empregá-la na produção literária e cultural, em sua própria língua materna.

Essa escrita visual direta de sinais beneficia o surdo porque é muito mais fácil escrever na língua com que se pensa. Por isso, SignWriting registra os sinais do ponto de vista expressivo, isto é, do sinalizador. Quando o surdo escreve o que pensa na língua em que se dá o pensar, tal pensar torna-se mais claro, preciso e formalizado (CAPOVILLA et al., 2013, p. 46).

Mais uma vez, assistimos à expressão "comunidade surda" ser substituída por "povo surdo", no contexto em que se discute um sistema de escrita para a Libras.

Um tal sistema de escrita visual direta de sinais traria múltiplos benefícios psicológicos e sociológicos. Permitiria à criança surda tirar vantagem das propriedades visuais de sua língua materna para pensar, comunicar-se e escrever numa única língua, o que aceleraria seu desenvolvimento linguístico e cognitivo, e a colocaria em pé de igualdade com a ouvinte. Ao mesmo tempo, como a aquisição do sistema secundário sempre resulta em reorganização, aprimoramento e desenvolvimento do primário, o uso de um tal sistema de escrita levaria naturalmente à

\footnotetext{
${ }^{4}$ A presença da expressão povo surdo não é unânime nos trabalhos sobre línguas de sinais, mas tem sido bastante recorrente em trabalhos recentes. No caso do presente trabalho, interessa-nos destacar o uso da expressão no contexto dos estudos que tratam da instrumentalização da Libras, mais especificamente.
} 
expansão, ao desenvolvimento e ao refinamento linguístico do sinal, culminando no enriquecimento da língua de sinais (na medida em que os sinais de grupos e subculturas variadas forem sendo incorporados) e em sua normatização como língua oficial da cultura surda e do povo surdo. Isto seria instrumental à constituição da identidade da cultura de sinais e do povo surdo, à sua integração espacial e temporal, no território geográfico e através das gerações, e ao seu desenvolvimento cultural e social pleno (CAPOVILLA et al., 2004, p. 268).

ELiS é outro sistema de escrita das Línguas de Sinais (LS), de base alfabética e linear, criado em 1997 em uma pesquisa de mestrado realizada por Mariângela Estelita Barros. Segundo a autora, este surgiu em decorrência da necessidade dos surdos de utilizarem uma escrita, para que assim lhes fosse permitida a reflexão e a expressão em sua própria língua materna.

Como discutimos anteriormente a propósito da formação das nações europeias, a adoção de uma escrita alfabética para as línguas vernáculas foi fundamentada no modelo latino, com a subdivisão da cadeia falada em unidades mínimas sonoras. Semelhante processo é possível de ser reconhecido na EliS. Nesse sistema, para fazer um paralelo com as unidades mínimas sonoras - fonema e fone, empregados na Fonologia e na Fonética -, serão propostos os termos visema e viso, respectivamente. Como explica Barros (2008),

Os símbolos do alfabeto ELiS, em vez de representarem "os sons elementares de uma linguagem", representam os visemas elementares de uma língua. Crio aqui o termo "visema" em equivalência ao termo fonema. Sendo o fonema uma unidade sonora de uma LO [língua oral], visema passa a ser uma unidade visual de uma LS [língua de sinais]. Em extensão a este novo termo, utilizo visêmico onde para as LO se diz fonológico; visético, no lugar de fonético; viso, ao invés de fone. (BARROS, 2008, p. 14).

Os símbolos representativos de visemas na ELiS são denominados informalmente de letras, como no alfabeto latino, ou mais tecnicamente, de visografemas, ou seja, unidades mínimas (-ema) escritas (graf-) dos visemas (vis-), uma nomenclatura específica para a escrita dos elementos das LS (BARROS, 2008, p. 25).

Em seu livro intitulado EliS: Sistema brasileiro de escrita das Linguas de Sinais, publicado em 2015, Barros chama atenção para a possibilidade de, usando-se o seu sistema de escrita para as línguas orais, elaborar um dicionário semasiológico “[...] com entradas em língua de sinais organizadas de maneira estritamente alfabética linear" (BARROS, 2015, p. 93). Nesse mesmo ponto, a autora discute a importância dos dicionários para o registro das línguas e exalta a possibilidade de um dicionário para as línguas de sinais ter a sua própria ordem 
alfabética, isto é, não recorrer ao equivalente em LO para estruturar a apresentação dos itens lexicais, diferentemente do que ocorre, por exemplo, com o Novo Deit-Libras.

Fica patente a importância de um sistema de escrita na gramatização de uma língua, como viemos discutindo ao longo deste trabalho. Ainda que se trate de uma língua visogestual, a necessidade de instrumentalizá-la nos moldes das línguas modernas, nos parece, explica a busca por um sistema de escrita.

Entretanto, a escassez, no contexto brasileiro, de material escrito em qualquer um dos sistemas propostos - aqui discutimos o SW e o ELiS - é notória e, consequentemente, a "alfabetização" dos surdos brasileiros em qualquer um desses sistemas é ainda bastante incipiente.

Analisando a difusão de seu sistema de escrita, Barros reconhece sua pouca penetração e afirma que

[...] mesmo sistemas de escrita mais antigos como o SignWriting e o HamNoSys, que já contam com mais experiências de ensino, ainda não se "firmaram" entre as comunidades de surdos, ou seja, ainda que haja bastante interesse em aprender os sistemas de escrita, não se veem seus usos sociais. Há, é verdade, publicações escritas nestes sistemas, inclusive publicações online (ver, por exemplo,

www.signwriting.org/library/children/), mas não há um engajamento geral das comunidades em suas produções e consumo destas (BARROS, 2008, p. 16).

As razões para tal estado de coisas são, certamente, diversas e complexas, mas mencionamos brevemente duas delas: a relação das línguas de sinais com as LO e a existência de novas tecnologias de informação. Barros analisa a situação e levanta a hipótese, não confirmada,

[...] de que a causa disto não seja uma falha nos sistemas de escrita, nem mesmo na divulgação destes entre as comunidades surdas. O motivo parece mais ser uma questão cultural de dominação das LO. A escrita em LS, seja em qual sistema for, ainda não é uma escrita "socialmente autorizada" (BARROS, 2008, p. 17).

De nossa parte, embora reconheçamos as consequências da hegemonia das LO em todos os aspectos das sociedades humanas, levantamos outra hipótese, que precisaria ser melhor investigada em trabalhos futuros. Isto é, a oficialização de Libras é contemporânea ao aparecimento de novas tecnologias que proporcionam o recurso à imagem e desfavorecem a percepção, por parte de muitos membros da comunidade surda brasileira, 
da necessidade de uma escrita, quando outras formas de comunicação mais rápidas, diretas e de fácil acesso estão disponíveis.

Há hoje, à disposição dos surdos, tecnologia digital que possibilita uma gama de dicionários digitais e aplicativos que permitem, inclusive, tradução instantânea, tais como ProDeaf Móvel, Libras IFZN, Falalibras e HandTalk, dentre outros. É possível constatar que esses vários sites e aplicativos exercem papel fundamental na padronização de Libras, do ponto de vista visogestual. Por outro lado, tornam a escrita menos necessária para atender às demandas imediatas de comunicação, constituindo, nos parece, um obstáculo à rápida propagação de um sistema de escrita nos moldes tradicionais.

Se as línguas vernáculas, durante o período do Renascimento, puderam contar com a recém-criada tecnologia da imprensa e a difusão de textos como forma de expansão da escrita e de sua oficialização, contenção da variação e estandardização, nos tempos atuais, o impacto de novas tecnologias digitais tem outras consequências sobre o processo de gramatização das línguas, sobretudo das línguas de sinais.

\section{Breves considerações finais}

Neste trabalho, comparamos o fenômeno da gramatização das línguas vernáculas, conforme propõe Auroux (2014), com o que observamos ocorrer com a Libras e seu papel na constituição da identidade do surdo brasileiro, culminando, inclusive, com a referência ao povo surdo, em explícita distinção do povo unificado em torno de uma língua oral, no nosso caso, o português.

Vimos como a busca por descrever e instrumentalizar a Libras nos moldes do que ocorreu com os vernáculos europeus é patente, com destaque para o papel da escrita na criação dos instrumentos linguísticos, como dicionários e gramáticas, que asseguram a preservação das línguas.

Entretanto, apontamos para uma mudança importante no quadro traçado por Auroux (2014). Ou seja, o recente processo de oficialização da Libras (iniciado em 2002) coincide com o aparecimento e a rápida divulgação de novas tecnologias de comunicação 
que, acreditamos, dão ao processo de instrumentalização da Libras características bastante peculiares, que demandam novas reflexões e investigações.

No contexto da breve discussão que nos propusemos a fazer aqui, arriscamos afirmar que o processo de gramatização a que se referiu Auroux (2014) parece estar em pleno desenvolvimento, com novas consequências para a padronização das línguas, a sua percepção enquanto língua de unidade de um povo e as práticas linguísticas humanas. Neste momento, ousamos dizer, a relação entre gramáticas, dicionários e escrita não se apresenta mais da mesma forma.

Assim sendo, novos estudos são necessários, uma vez que, mesmo para as línguas orais, essas novas tecnologias, acreditamos, afetarão as línguas e nossas formas de concebêlas, assim como ocorreu com a invenção da imprensa, quando, nas palavras de Auroux (2014, p. 51), “o fenômeno da escrita da língua muda de dimensão".

\section{Referências}

AUROUX, S. A revolução tecnológica da gramatização. Campinas: Ed. da Unicamp, 2014.

BARROS, Mariângela Estelita. EliS: sistema brasileiro de escrita das línguas de sinais. Porto Alegre: Ed. Penso, 2015.

BARROS, Mariângela Estelita. EliS - Escrita das línguas de sinais: proposta teórica e verificação prática. Tese (Doutorado em Linguística). Florianópolis: Universidade Federal de Santa Catarina, 2008.

BRANDÃO, Flávia. Dicionário ilustrado de Libras. São Paulo: Global, 2011.

CAPOVILLA, F. C. et al. O desafio do bilinguismo na educação do surdo: descontinuidade entre a língua de sinais e a escrita alfabética e estratégias para resolvê-la. Neuropsicologia e aprendizagem: uma abordagem multidisciplinar. 2. ed. São Paulo: Memnon; Capes; Sociedade Brasileira de Neuropsicologia, 2004. Disponível em: <http://www.ip.usp.br/lance/capitulos.html>. Acesso em: 24 de Jun. 2015.

CAPOVILLA, Fernando César; RAPHAEL, Walkíria Duarte (Orgs.). Enciclopédia da Língua de Sinais Brasileira: o mundo do Surdo em Libras. 1. ed. 2. reimp. São Paulo: (Fundação) Vitae/Fapesp/Capes/Ed. da USP, v.1, 2011.

Dicionário enciclopédico ilustrado trilíngüe da língua de sinais brasileira. 2. ed. Ilustrações de Silvana Marques. V. 1: sinais de A a L; V. 2: sinais de M a Z. São Paulo: USP/Imprensa Oficial do Estado, 2001. 
CAPOVILLA, Fernando César; RAPHAEL; Walkíria Duarte; MAURICIO, Aline Cristina L. (Org.). Novo Deit-Libras: dicionário enciclopédico ilustrado trilíngue da língua de sinais brasileira (Libras) baseado em linguística e Neurociências cognitivas. 3. ed. V. 1: sinais de A a H. São Paulo: Editora da Universidade de São Paulo/Inep; CNPq/Capes; Obeduc, 2013.

FERREIRA, Lucinda. Por uma gramática de línguas de sinais. Rio de Janeiro: Tempo Brasileiro, 2010.

GRASSI, Dayse; ZANONI, Graziely Grassi; VALENTIN, Silvana M. Lopes. Língua Brasileira de Sinais: aspectos linguísticos e culturais. Projeto Saber, Revista Trama, v. 7, n. 14, 2011. Disponível em:

$<$ http://e-revista.unioeste.br/index.php/trama/article/view/5786>. Acesso em: 19 de Maio 2015.

LIRA, Guilherme; SOUZA, Tanya. Dicionário da Lingua de Sinais Brasileira: Acessibilidade Brasil, versão 2.1. 2008. Disponível em: < http://www.acessibilidadebrasil.org.br/libras/>. Acesso em 25 de Abr. 2018.

PEREIRA, Maria Cristina Cunha et al. Libras: conhecimento além dos sinais. São Paulo: Pearson Prentice Hall, 2011.

QUADROS, Ronice Müller; SCHMIEDT, Magali L. P. Ideias para ensinar português para alunos surdos. Brasília: MEC/Seesp, 2006.

ROBINS, R. H. Pequena história da Linguística. Rio de Janeiro: Ao Livro Técnico, 1979.

SACKS, Oliver. Apresentação. In: CAPOVILLA, Fernando César; RAPHAEL, Walkíria Duarte (Org.). Dicionário enciclopédico ilustrado trilíngüe da língua de sinais brasileira. 2 ed. V. 1. Ilustrações de Silvana Marques. São Paulo: USP/Imprensa Oficial do Estado, 2001. Letras, 2010.

Vendo vozes: uma viagem ao mundo dos surdos. São Paulo: Companhia das

STUMPF, Marianne R. Aprendizagem de escrita de língua de sinais pelo sistema SignWriting: línguas de sinais no papel e no computador. Tese (Doutorado em Informática na Educação). Porto Alegre: Universidade Federal do Rio Grande do Sul, 2005. 


\section{Résumé}

Dans ce travail, nous soutenons l'idée d'être possible d'articuler théoriquement le processus d'outillage de la langue des signes brésilienne avec ce qui s'est passé avec les langues vernaculaires au cours de la Renaissance, lorsqu'il est arrivé ce qu' Auroux (2014) appelle mouvement de la grammatisation massive des langues $d u$ monde. Différement $d u$ contexte d'outillage des langues vernaculaires, les systèmes d'écriture proposés se fondent sur très peu de matériaux et $<<$ l'alphabétisation $>>$ des sourds brésilliens dans la langue des signes est encore assez. rudimentaire. Il nou semble que la cause d'une telle situation est bien l'hégémonie de la langue portugaise. Notre bypothèse est que l'émergence de nouvelles technologies qui permettent l'image en mouvement défavorisent la perception de la nécessité d'une écriture pour les sourds. Pour développer notre réflexion, nous nous fondons sur les apports de l'bistoriographie, en particulier ces d'Auroux (1992), ainsi que sur d'autres auteurs abordant le processus de description de la langue des signes brésilienne et la création d'un système d'écriture de celle-ci, comme Capovilla et l'outres (2001; 2004; 2011; 2013) et Barros (2008; 2015).

Mots-clés: Libras. Grammatisation. Écriture. Peuple sourd 